\title{
Effects of doctors' empathy abilities on the cellular immunity of patients with advanced prostate cancer treated by orchiectomy: the mediating role of patients' stigma, self-efficacy, and anxiety
}

This article was published in the following Dove Press journal:

Patient Preference and Adherence

\author{
Ningxi Yang ${ }^{1,2}$ \\ Han Xiao' \\ Wei Wang' \\ Shiyue $\mathrm{Li}^{1, *}$ \\ Hong Yan' \\ Yifang Wang ${ }^{2, *}$
}

'Department of Epidemiology, School of Health Sciences, Wuhan University, Wuhan, Hubei, People's Republic of China; ${ }^{2}$ Department of Medical Humanities, Institute of Medical Humanities, Peking University, Beijing, People's Republic of China

*These authors contributed equally to this work
Correspondence: Shiyue Li

Department of Epidemiology, School

of Health Sciences, Wuhan University,

No II 5 Donghu Road, Wuhan, Hubei,

People's Republic of China

Tel/fax +8627687591/8

Email lsywhd@sina.com

\section{Yifang Wang}

Department of Medical Humanities, Institute of Medical Humanities, Peking University, No 38 Xueyuan Road, Haidian, Beijing 100191, People's

Republic of China

Tel +861082801832

Fax +862768758648

Email wyf6959_pku@sina.com
Background: The empathy of doctors is closely related to patients' outcomes. This research aimed to examine whether patients' stigma, self-efficacy, and anxiety mediate the relationship between doctors' empathy and cellular immunity in patients with advanced prostate cancer treated by orchiectomy.

Participants and methods: Data on the empathy of doctors and the demographics, disease condition, stigma, self-efficacy, and anxiety of patients were collected. Patients' psychological indicators and cellular immunity were measured at admission, after 14 days, and after 3 months. The variance analysis test was used to compare the immune indices at the three time points. At T3, a multivariate linear regression model was used to analyze the factors that influenced the immune index. Pearson correlation analysis and structural equation modeling were used to examine the relationships among patients' stigma, self-efficacy, anxiety, and cellular immunity and doctors' empathy.

Results: At the three time points, all three psychological indicators of the patients were statistically significant. Among the immune indices, only the change in the percentage of NK cells (NK subset) was statistically significant, while the changes in the percentages of $\mathrm{CD}^{+}, \mathrm{CD}^{+}$, $\mathrm{CD}^{+}$, and $\mathrm{B}$ cells were not statistically significant. The doctors' empathy showed negative relationships with patients' stigma and anxiety and a positive relationship with patients' selfefficacy. Patients' stigma and anxiety were negatively associated with NK subset, while patients' self-efficacy showed a positive relationship with NK subset. Anxiety was positively related to stigma and negatively related to self-efficacy. Therefore, the effect of the doctors' empathy on the patients' NK subset was mediated by the patients' stigma, self-efficacy, and anxiety.

Conclusion: Doctors' empathy affected the NK subset in advanced prostate cancer patients and was related to the patients' stigma, self-efficacy, and anxiety. In addition, anxiety directly affected stigma and self-efficacy. Thus, medical staff should focus on improving their empathy toward patients. Interventions that focus on patients' anxiety, stigma, and self-efficacy may be helpful to improve immunity.

Keywords: empathy, prostate cancer, doctor, cellular immunity, stigma, self-efficacy, anxiety

\section{Introduction}

Prostate cancer is one of the most common malignant tumors in the male genitourinary system, and it poses a serious threat to patient health. Prostate cancer not only harms the bodies and lives of patients but also causes anxiety, depression, and other negative emotions, and the lesion's location in the male reproductive organ may often 
impact the patients' feelings of self-respect. ${ }^{1}$ For patients with advanced prostate cancer, castration can inhibit the secretion of testosterone, which helps inhibit the growth of prostate cancer cells. Castration is divided into drug castration and surgical castration. ${ }^{2}$ The surgical operation that patients undergo during castration is an orchiectomy, which often causes patients to suffer great psychological trauma and stigma and a decreased sense of dignity. Therefore, the psychological health problems of these patients demand greater attention.

Psychology and immunity are interrelated. Psychoneuroimmunology is currently a key area of research focus, especially in relation to cancer patients. Many studies have considered the effect of the patients' own psychological indicators on their immunity or the effect of psychological intervention on the patients' immune function. Relationship between patients' mood and immunity has been confirmed. ${ }^{3,4}$ Unlike other studies, the present study not only performed a survey of the psychological health status of prostate cancer patients treated by orchiectomy but also examined the effects of doctors' empathy on various aspects of patients' psychological health, such as stigma, self-efficacy, and anxiety, along with patients' cellular immunity. The mechanism by which doctors' empathy influences patients' immunity is the focus of this study. Although published studies have tested the relationship between doctors' empathy and patients' outcomes, these studies focused on the patients' psychological parameters rather than on physiological indices, ${ }^{5}$ highlighting the innovation of the present research.

Empathy refers to the ability to understand another's situation and to respond appropriately to his or her feelings. It is a relatively stable individual trait. ${ }^{6}$ The empathy of medical staff members is of great importance because it affects the doctor-patient relationship, patients' satisfaction, the quality of patient-centered care, and patients' outcomes. ${ }^{7-9}$ Currently, developed countries attach great importance to empathy education of medical staff. For example, the American Association of Medical Colleges (AAMC) requires all medical schools to provide courses for improving students' empathy. ${ }^{10}$ However, medical humanities education, such as coursework in empathy, is inadequate in developing countries. Thus, the purpose of this study was to confirm the effect of doctors' empathy on the physical and mental health of patients with prostate cancer using a Chinese sample. The authors recommend that medical staff aim to increase their attention to patients' mental health and to improve their empathy.
In this study, the following hypotheses are proposed.

Hypothesis 1: doctors' empathy directly affects patients' cellular immunity.

Hypothesis 2: patients' stigma, self-efficacy, and anxiety mediate the relationship between doctors' empathy and patients' cellular immunity.

\section{Participants and methods Participants}

The participants were 175 prostate cancer patients who were treated between October 2016 and January 2018 at five hospitals in north China. The patients met the following predetermined criteria for eligibility: 1) each patient was diagnosed with prostate cancer and was in the T3 or T4 stage; 2) each patient was hospitalized for at least 7 days to undergo orchiectomy; 3 ) each patient was aware of his illness, able to provide informed consent, and able to complete all questionnaires with full awareness of his cancer diagnosis; and 4) each patient underwent the operation within 1 month from when they were diagnosed. The following exclusion criteria were used: 1) intake of drugs that affect immune function, 2) severe malnourishment, 3) radiotherapy or chemotherapy within 3 months of the study, and 4) treatment with traditional Chinese medicine within the prior 3 months. In this study, the patients were treated by 41 doctors from Urology Surgery. As the chief physician during the patient's hospitalization, the doctor is responsible for the treatment and health education of his or her patients. Additionally, the doctor aims to pacify patients when they have negative emotions and to answer their questions. The Wuhan University School of Medicine's Ethics Committee approved this study (no 20160928). All participating patients provided written informed consent.

\section{Procedures}

The purpose of this study was to perform a mediation analysis to examine whether the relationship between doctors' empathy and patients' cellular immunity is mediated by patients' stigma, self-efficacy, and anxiety. The relationships among the mediator variables were also measured. The main steps used to test these relationships were as follows: 1) on the day of admission (T1), a cross-sectional, anonymous questionnaire including questions on essential information and disease conditions was administered to the prostate cancer patients; their stigma, self-efficacy, and anxiety were measured on T1, T2 (14 days later), and T3 (3 months later); blood samples were also collected at these times to assess cellular immunity; the empathy of each doctor was measured when the study began; 2) patients' stigma, self-efficacy, anxiety, 
and cellular immunity at $\mathrm{T} 1, \mathrm{~T} 2$, and $\mathrm{T} 3$ were compared to show trend variations, and the effects of demographics and disease condition on immunity at T3 were analyzed; and 3 ) in a structural equation model, the correlations among the patients' stigma, self-efficacy, anxiety and immunity with the doctors' empathy were measured at T3. Then, the role of the psychological variables and the relationships among them were presented.

\section{Measures}

\section{Patient questionnaire}

This essential information section was used to collect sociodemographic information, such as age, marital status, educational background, place of residence, monthly family income per capita, medical insurance, and family relationships. Disease condition (staging) information was completed by the doctors.

To assess stigma, the Social Impact Scale (SIS) was used. The scale was constructed by Fife and Wright ${ }^{11}$ in 2000. The scale comprises 24 items answered on a 4-point Likert scale, with each response score ranging from 1 to 4 . Four dimensions corresponding to social rejection, financial insecurity, internalized shame, and social isolation were included. Scores on the SIS range from 4 to 96, with higher scores indicating greater stigma. This scale is widely used and has good reliability and validity. The Chinese version was used for this study. ${ }^{12}$

To measure self-efficacy, the Brief Version of the Cancer Behavior Inventory (CBI-B) was used. This inventory is a 12-item scale of self-efficacy for cancer patients derived from the longer 33-item version (CBI-L) constructed by Carolyn. ${ }^{13,14}$ There are four dimensions: 1$)$ maintaining independence and positive attitude, 2) participating in medical care, 3) coping and stress management, and 4) managing affect. For the 12 questions, each response score ranges from 1 to 9 . Scores on the CBI-B range from 12 to 108 and higher scores indicate greater self-efficacy. ${ }^{13,14}$

To measure anxiety, the Hospital Anxiety and Depression Scale (HADS) was used to assess depressive mood. The HADS is a 14-item self-assessment scale that consists of seven items used to screen for anxiety (HADS-a) and seven items used to screen for depression (HADS-d). Each item has a 4-point (0-3) Likert-type scale, while each subscale totals from 0 to 21 and the two scales total from 0 to 42 . Higher scores indicate more severe anxiety or depression. ${ }^{15}$ The optimal cutoffs for both the HADS-a and the HADS-d were identified as $\geq 8$, with an optimal cutoff for the HADS-total of $15 .{ }^{16}$ Participants are asked to choose their response for each question according to their actual circumstances within the last month. In this study, only the HADS-d was used to measure the depressive mood of the patients.

\section{Patient cellular immunity}

To control diurnal variations, peripheral venous blood samples were collected between 9 am and 10 am before the questionnaires were completed. Patients' cellular immunity tests were completed by the professional staff working at the clinical laboratory of the hospital. The immunity tests evaluated $\mathrm{T}$-cell subsets, including the percentage of total $\mathrm{T}$ cells $\left(\mathrm{CD}^{+}\right)$, helper T cells $\left(\mathrm{CD}^{+}\right)$, cytotoxic $\mathrm{T}$ cells $\left(\mathrm{CD}^{+}\right)$, NK cells $\left(\mathrm{CD}^{+} 6^{+}\right)$, and $\mathrm{B}$ cells $\left(\mathrm{CD} 19^{+}\right)$. Flow cytometry was used to assess $\mathrm{T}$ - and NK-cell counts with a Cytomics ${ }^{\mathrm{TM}}$ FC 500 series instrument from Beckman Coulter (Brea, CA, USA). Reagents from BD Bio-Engineering Co., Ltd. (Franklin Lakes, NJ, USA), were used. Cells were fixed in 3\% formaldehyde in an isotonic azide-free solution (Beckman Coulter). Labeled antibodies were added at the recommended concentrations, and then, cells were washed. Cells were cultured in the dark, and then, excess antibodies were washed out.

\section{Doctors' empathy}

The Chinese version of the Jefferson Scale of Empathy (JSE) was used to measure individual differences in empathy among the doctors. The scale was first developed in 2001 at Jefferson Medical College to assess empathy in the context of patient care and medical education. ${ }^{17}$ The scale consists of three dimensions (compassion care, perspective taking, and standing in the patient's shoes). The assessment includes 20 items that are answered on a 7-point Likert scale. Each response is converted into a numerical score ranging from 1 to 7 ( 1 indicates "strongly disagree" and 7 indicates "strongly agree"). ${ }^{18}$ Therefore, scores on the JSE range from 20 to 140 , with higher scores indicating stronger empathy levels. There is widespread support for the JSE across many countries, and it has good reliability and validity. ${ }^{19}$ The Chinese version of the JSE was used in this study to measure doctors' empathy. This scale has satisfactory reliability and validity when applied in clinical studies and has been widely used in China. ${ }^{20}$

\section{Statistical analyses}

The variance analysis test was used to compare immune indices at T1, T2, and T3. A multivariate linear regression model was used to analyze the factors influencing the immune index that showed statistically significant differences between T1 and T3. Pearson's correlation analysis 
was used to preliminarily measure the relationships among the patients' stigma, self-efficacy, and immune indices and doctors' empathy. In this research, alpha $=0.05$, and the tests were two tailed. The above data processing and analyses were carried out using SAS Version 9.4 for Windows. To further investigate the relationships among patients' stigma, self-efficacy, anxiety, and immune indices and doctors' empathy, structural equation modeling (SEM) was performed using AMOS Version 5. The indices of the model's fit to the data were evaluated with the following statistics: goodness-of-fit index (GFI) $(>0.9)$, comparative fit index $(\mathrm{CFI})(>0.9)$, root mean square error of approximation (RMSEA) $(<0.05)$, and Chi-square/df $(<2)$.

\section{Results}

\section{Sample}

All the selected doctors agreed to participate in the study. They were all males with a median age of $41.26 \pm 6.18$ years. A total of 175 patients participated. The average age of the sample patients was $61.28 \pm 7.64$ years. The average number of hospitalization days was $6.46 \pm 0.79$ days. The patients' demographics and disease conditions are shown in Table 1.

\section{Comparison of cellular immune indices and psychological indicators of patients at admission, after 14 days, and after 3 months}

Comparisons of the patients' cellular immune indices and psychological indicators at admission, after 14 days, and after 3 months are shown in Table 2. At the three time points, changes in the NK subset were statistically significant $(P<0.0001)$. There were no significant differences in the proportions of CD3, CD4, CD8, and B cells $(P>0.05)$. The changes in patients' anxiety, self-efficacy, and stigma were also statistically significant $(P<0.0001)$.

\section{Effect of demographic characteristics and disease condition on the patients' NK subsets}

The results of the multivariate linear regression analysis are shown in Table 3. There was a statistically significant difference in the NK subset between smokers and non-smokers $(P<0.001)$. This finding indicates that smoking is an influential factor in the NK subset. Moreover, the difference in the NK subset at 3 months compared with baseline is another influential factor of the NK subset.
Table I Patients' demographics and disease conditions

\begin{tabular}{|c|c|c|}
\hline Variable & Number & $\%$ \\
\hline \multicolumn{3}{|l|}{ Educational background } \\
\hline Primary school or below & 42 & 24 \\
\hline Junior middle school & 77 & 44 \\
\hline Senior middle school & 44 & 25.1 \\
\hline College or above & 12 & 6.9 \\
\hline \multicolumn{3}{|l|}{ Marital status } \\
\hline Unmarried & 3 & 1.7 \\
\hline Married & 152 & 86.9 \\
\hline Divorced or widowed & 20 & 11.4 \\
\hline \multicolumn{3}{|l|}{ Home place } \\
\hline Countryside & 58 & 33.1 \\
\hline County town & 30 & 17.2 \\
\hline Urban area & 87 & 49.7 \\
\hline \multicolumn{3}{|l|}{ Monthly family income per capita (yuan) } \\
\hline$<3,000$ & 64 & 36.6 \\
\hline $3,000-5,000$ & 87 & 49.7 \\
\hline$>5,000$ & 24 & 13.7 \\
\hline \multicolumn{3}{|l|}{ Medical insurance } \\
\hline Private health care provision & 39 & 22.3 \\
\hline Social security or commercial insurance & 93 & 53.1 \\
\hline New rural cooperative medical system & 35 & 20 \\
\hline Socialized medicine & 8 & 4.6 \\
\hline \multicolumn{3}{|l|}{ Self-evaluation family relationship } \\
\hline Poor & 38 & 21.7 \\
\hline General & 65 & 37.1 \\
\hline Good & 72 & 41.2 \\
\hline \multicolumn{3}{|l|}{ Tumor metastasis } \\
\hline Yes & 81 & 46.3 \\
\hline No & 94 & 53.7 \\
\hline \multicolumn{3}{|l|}{ Long-term drinking } \\
\hline Yes & 13 & 7.4 \\
\hline No & 162 & 92.6 \\
\hline \multicolumn{3}{|l|}{ Smoking } \\
\hline Yes & 52 & 29.7 \\
\hline No & 123 & 70.3 \\
\hline \multicolumn{3}{|l|}{ Insomnia } \\
\hline Yes & 13 & 7.4 \\
\hline No & 162 & 92.6 \\
\hline
\end{tabular}

\section{Correlations of doctors' empathy with patients' stigma, self-efficacy, anxiety, and NK subset}

Pearson's correlation was used to analyze the relationships of patients' stigma, self-efficacy, anxiety and NK subset with doctors' empathy, as shown in Table 4. The results showed that the doctors' empathy was negatively correlated with patients' stigma $(r=-0.648, P<0.01)$ and anxiety $(r=-0.643$, $P<0.01)$ and positively correlated with patients' self-efficacy $(r=0.542, P<0.01)$ and NK subset $(r=0.508, P<0.01)$. Patients' self-efficacy was negatively correlated with stigma $(r=-0.613, P<0.01)$ and anxiety $(r=-0.690, P<0.01)$ and positively correlated with NK subset $(r=0.608, P<0.01)$. 
Table 2 Comparison of cellular immune indices and psychological indicators of patients at admission, after I4 days, and after 3 months

\begin{tabular}{llllll}
\hline$\%$ & At admission & After I4 days & After 3 months & F & P-value \\
\hline CD3 & $58.818 \pm 7.209$ & $59.314 \pm 6.543$ & $60.032 \pm 6.878$ & 3.369 & 0.255 \\
CD4 & $34.482 \pm 6.323$ & $35.122 \pm 5.557$ & $28.721 \pm 6.022$ & 0.512 & 0.599 \\
CD8 & $28.346 \pm 6.127$ & $29.010 \pm 6.262$ & $28.872 \pm 7.021$ & 0.504 & 0.606 \\
B & $7.648 \pm 2.141$ & $8.081 \pm 2.330$ & $8.172 \pm 1.961$ & 2.928 & 0.054 \\
NK & $16.823 \pm 7.112$ & $19.313 \pm 8.442$ & $21.778 \pm 8.136$ & 18.670 & $<0.0001$ \\
Anxiety & $15.429 \pm 4.872$ & $18.12 \pm 5.218$ & $11.269 \pm 5.618$ & 75.750 & $<0.0001$ \\
Self-efficacy & $67.691 \pm 13.558$ & $60.352 \pm 14.869$ & $68.326 \pm 15.860$ & 15.720 & $<0.0001$ \\
Stigma & $68.123 \pm \mid 14.321$ & $72.652 \pm 15.501$ & $63.303 \pm 16.495$ & 16.000 & $<0.0001$ \\
\hline
\end{tabular}

Note: Data presented as mean \pm SD.

Patients' stigma was negatively correlated with NK subset $(r=-0.610, P<0.01)$ and positively correlated with anxiety $(r=0.699, P<0.01)$. Patients' anxiety was negatively correlated with NK subset $(r=-0.688, P<0.01)$. The above findings lay the foundation for further analyses of the relationships among the variables.

\section{Multiple mediating effects among doctors' empathy and patients' stigma, self-efficacy, and NK subset}

According to the above analysis, a correlation among doctors' empathy and patients' stigma, self-efficacy, anxiety, and NK subset was identified. To further clarify the relationships

Table 3 The effects of demographics and disease on the patients' NK activity

\begin{tabular}{|c|c|c|c|c|}
\hline & $\beta$ & $\begin{array}{l}\text { Standard } \\
\text { error }\end{array}$ & $t$ & P-value \\
\hline Constant term & 18.862 & 7.775 & 2.430 & 0.016 \\
\hline Age & -0.023 & 0.074 & -0.320 & 0.753 \\
\hline Hospitalization days & 0.448 & 0.733 & 0.610 & 0.542 \\
\hline Difference value of NK & 1.136 & 0.174 & 6.520 & $<0.0001$ \\
\hline \multicolumn{5}{|c|}{ Education (reference group: primary school or below) } \\
\hline Junior middle school & -0.790 & 1.552 & -0.510 & 0.612 \\
\hline Senior middle school & 0.117 & 1.984 & 0.060 & 0.953 \\
\hline College or above & -0.014 & 2.858 & 0.004 & 0.996 \\
\hline \multicolumn{5}{|l|}{ Marriage (reference group: unmarried) } \\
\hline Married & -4.166 & 4.416 & -0.940 & 0.347 \\
\hline Divorced or widowed & -2.397 & 4.758 & -0.500 & 0.615 \\
\hline \multicolumn{5}{|l|}{ Home place (reference group: countryside) } \\
\hline County town & -0.710 & 2.229 & -0.320 & 0.751 \\
\hline Urban area & -2.679 & 2.335 & -1.150 & 0.253 \\
\hline \multicolumn{5}{|c|}{ Monthly family income per capita (yuan) (reference group: $<3,000$ yuan) } \\
\hline $3,000-5,000$ & 0.181 & 1.642 & 0.110 & 0.913 \\
\hline$>5,000$ & -2.003 & 2.142 & -0.930 & 0.351 \\
\hline \multicolumn{5}{|c|}{ Medical insurance (reference group: private health care provision) } \\
\hline Social security or commercial insurance & 3.367 & $1.77 \mid$ & 1.900 & 0.059 \\
\hline New rural cooperative medical system & 0.690 & 2.038 & 0.340 & 0.736 \\
\hline Socialized medicine & -1.198 & 2.959 & -0.400 & 0.686 \\
\hline \multicolumn{5}{|c|}{ Self-evaluation family relation (reference group: poor) } \\
\hline General & I.I05 & 1.628 & 0.680 & 0.498 \\
\hline Good & 1.402 & 1.826 & 0.770 & 0.444 \\
\hline \multicolumn{5}{|l|}{ Transfer (reference group: no) } \\
\hline Yes & -0.239 & 1.353 & -0.180 & 0.860 \\
\hline \multicolumn{5}{|l|}{ Long-term drinking (reference group: no) } \\
\hline Yes & 0.280 & 2.259 & 0.120 & 0.902 \\
\hline \multicolumn{5}{|l|}{ Smoking (reference group: no) } \\
\hline Yes & -3.741 & 1.250 & -2.990 & 0.003 \\
\hline \multicolumn{5}{|l|}{ Insomnia (reference group: no) } \\
\hline Yes & 0.183 & 2.146 & 0.090 & 0.932 \\
\hline
\end{tabular}


Table 4 The correlations among doctors' empathy and patients' stigma, self-efficacy, anxiety, and NK subset

\begin{tabular}{|c|c|c|c|c|c|c|}
\hline Item & Score & Empathy & Self-efficacy & Stigma & Anxiety & NK subset \\
\hline Empathy & $102.740 \pm 13.356$ & 1 & & & & \\
\hline Self-efficacy & $68.990 \pm I 5.345$ & $0.542 *$ & I & & & \\
\hline Stigma & $63.30 \pm 16.495$ & $-0.648^{*}$ & $-0.613^{*}$ & I & & \\
\hline Anxiety & $\mid 1.270 \pm 5.618$ & $-0.643^{*}$ & $-0.690 *$ & $0.669 *$ & I & \\
\hline NK subset & $21.778 \pm 8.136$ & $0.508 *$ & $0.654 *$ & $-0.610 *$ & $-0.688^{*}$ & I \\
\hline
\end{tabular}

Note: $* p<0.01$

among these factors, the path analysis method was adopted to construct multiple intermediary models and the AMOS software was used to investigate the indices of the hypothesis model described earlier. The data fit the hypothesis model well ( $\mathrm{GFI}=0.935, \mathrm{CFI}=0.984$, adjusted goodness-of-fit index $=0.900$, normed fit index $=0.941$, RMSEA $=0.045, \chi^{2}=80.097$, and $\chi^{2}$ $d f=1.358)$. These values indicate that all the instruments were fairly reliable, and their validity was acceptable. In this model, the path coefficient, that the doctors' empathy directly affects the patients' NK subset, was not significant, indicating that Hypothesis 1 was invalid. The final model is shown in Figure 1.

The normalized path coefficient is shown in Table 5. The path coefficients for the effects of doctors' empathy were -0.616 on patients' stigma, -0.728 on patients' anxiety, and 0.371 on patients' self-efficacy. The path coefficients for the effects of patients' anxiety were 0.264 on patients' stigma, -0.482 on patients' self-efficacy, and -0.264 on NK subset. The path coefficient of the effects of patients' stigma on NK subset was -0.208 , and the path coefficient of the effects of patients' self-efficacy on NK subset was 0.37 . These values were significant at alpha $=0.05$.

To verify the mediating effect, bootstrapping was used. The confidence interval was set to $95 \%$, and the number of selfsamples was set to 5,000. The obtained results are shown in Tables 6 and 7. The analysis revealed that the mediating effect was significant when 0 was not contained in the confidence interval. In this study, the overall mediating effect of the three intermediary variables was significant. The general effect was 0.315 (95\% CI: $0.240-0.410)$. In the three mediating paths, the anxiety, self-efficacy and stigma played significant intermediary roles, and the effects were 0.143 (95\% CI: 0.073-0.227), 0.095 (95\% CI: 0.036-0.163), and 0.077 (95\% CI: 0.005-0.176).

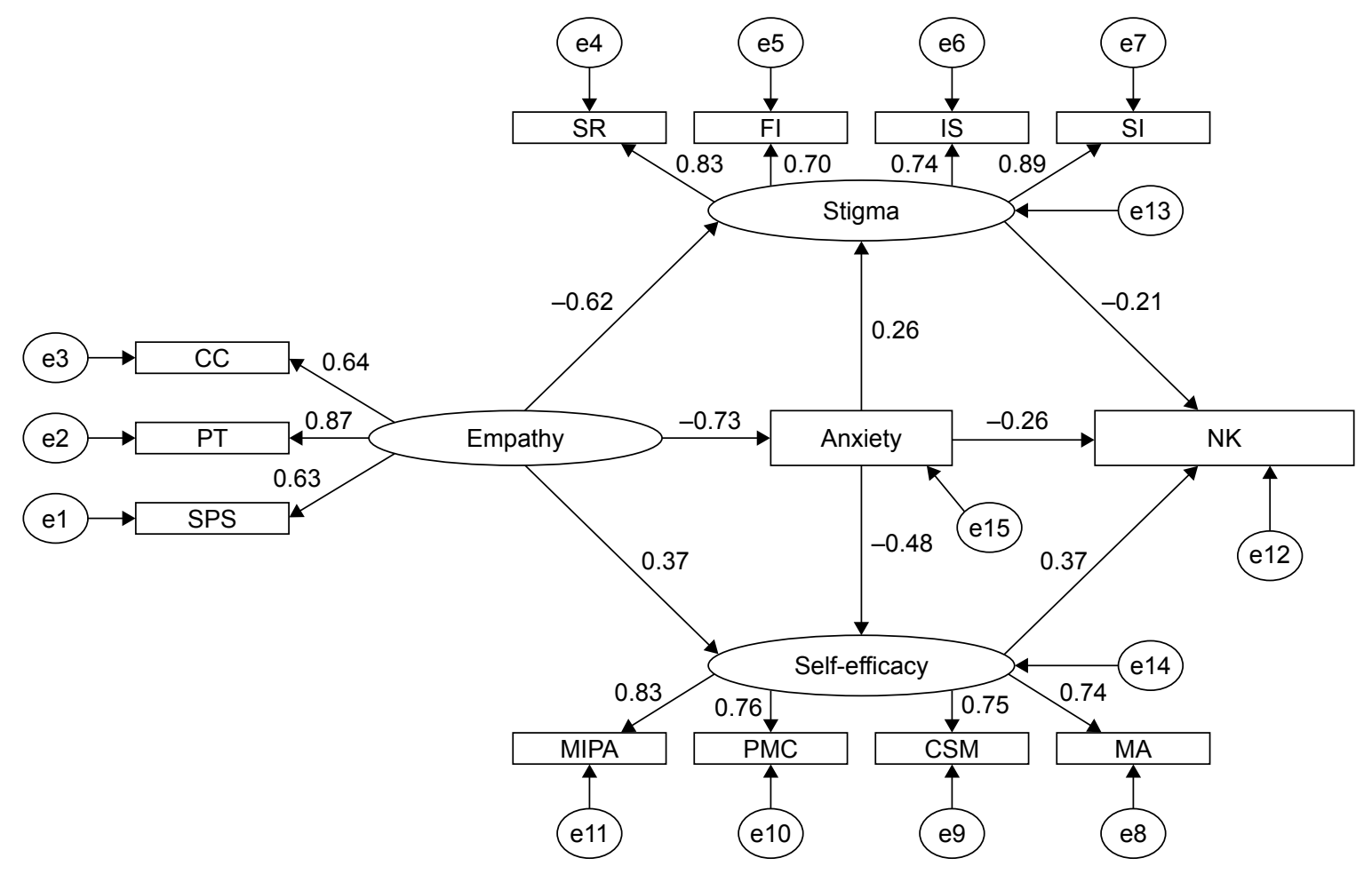

Figure I The model of relationships among doctors' empathy abilities and patients' stigma, self-efficacy, anxiety, and NK subset.

Abbreviations: MIPA, maintaining independence and positive attitude; PMC, participating in medical care; CSM, coping and stress management; MA, managing affect; SPS, standing in the patient's shoes; PK, perspective taking; CC, compassion care; SR, social rejection; FI, financial insecurity; IS, internalized shame; SI, social isolation. 
Table 5 Normalized path coefficients

\begin{tabular}{|c|c|c|c|c|}
\hline Path & $\begin{array}{l}\text { Normalized } \\
\text { path coefficient }\end{array}$ & SE & CR & $P$-value \\
\hline Doctors' empathy $\rightarrow$ patients' stigma & -0.616 & 0.558 & -5.079 & $<0.001$ \\
\hline Doctors' empathy $\rightarrow$ patients' self-efficacy & 0.371 & 0.278 & 3.411 & $<0.001$ \\
\hline Doctors' empathy $\rightarrow$ patients' anxiety & -0.728 & 0.431 & -7.674 & $<0.001$ \\
\hline Patients' anxiety $\rightarrow$ stigma & 0.264 & 0.097 & 2.747 & 0.006 \\
\hline Patients' anxiety $\rightarrow$ self-efficacy & -0.482 & 0.056 & -4.882 & $<0.001$ \\
\hline Patients' anxiety $\rightarrow$ NK subset & -0.264 & 0.136 & -2.806 & 0.005 \\
\hline Patients' stigma $\rightarrow$ NK activity & -0.208 & 0.121 & -2.452 & 0.014 \\
\hline Patients' self-efficacy $\rightarrow$ NK activity & 0.370 & 0.252 & 3.760 & $<0.001$ \\
\hline
\end{tabular}

Abbreviations: CR, construct reliability; SE, standard error.

After removing the mediating effect of the three variables, the effect of doctors' empathy on patients' NK subset was not significant. This indicated that patients' anxiety, self-efficacy, and stigma together completely explained the mediating role between doctors' empathy and patients' NK subset.

\section{Discussion}

This study revealed that among the five cell immunoassay indices measured when the patient was admitted to the hospital, after 14 days, and after 3 months, only changes in the NK subset were statistically significant. The influences of demography and disease condition on the NK subset were further analyzed, and the results showed that smoking was the most influential factor, consistent with the results of previous research. ${ }^{21}$ Another influential factor was the difference in the NK subset (the 3-month NK subset minus the baseline NK subset), which indicated that the individual immune function of patients was related to their postoperative immune status. In addition, changes in patients' stigma, self-efficacy, and anxiety were significant at the three time points. Patients exhibited significantly increased anxiety and stigma and significantly reduced self-efficacy at 14 days after being hospitalized. At 3 months, their psychological indicators had significantly improved. This suggested that careful attention should be paid to patients' mental state changes, especially at 14 days after admission, when they had just recently undergone orchiectomy.

Through Pearson correlation analysis and structural equation, the relationships between doctors' empathy and patients'

Table 6 Bootstrap indirect effects analysis of nonparametric ratios

\begin{tabular}{|c|c|c|c|c|}
\hline \multirow{2}{*}{$\begin{array}{l}\text { Mediating } \\
\text { effect }\end{array}$} & \multirow[t]{2}{*}{ Effect } & \multirow{2}{*}{$\begin{array}{l}\text { Standard } \\
\text { error }\end{array}$} & \multicolumn{2}{|l|}{$95 \% \mathrm{Cl}$} \\
\hline & & & Boot LLCI & Boot ULCL \\
\hline Gross effect & 0.315 & 0.043 & 0.240 & 0.410 \\
\hline Anxiety & 0.143 & 0.039 & 0.073 & 0.227 \\
\hline Self-efficacy & 0.095 & 0.032 & 0.036 & 0.163 \\
\hline Stigma & 0.077 & 0.045 & 0.005 & 0.176 \\
\hline
\end{tabular}

Abbreviations: $\mathrm{LLCl}$, lower level confidence level; ULCL, upper level confidence level. stigma, self-efficacy, anxiety, and cellular immunity were examined in a cross-sectional sample of Chinese prostate cancer patients. The two hypotheses proposed above were tested.

Regarding the first hypothesis that doctors' empathy directly affects patients' cellular immunity, the results suggested that this hypothesis should be rejected. When the intermediary variable is removed, the effect of doctors' empathy on patients' NK subset was not significant, which suggests that the doctors' empathy did not directly affect the patients' NK subset.

The second hypothesis that patients' stigma, self-efficacy, and anxiety mediate the relationship between doctors' empathy and patients' cellular immunity was confirmed. The results proved that patients' stigma and self-efficacy fully mediated the relationship between doctors' empathy and patients' NK subset. This finding indicates that the effects of doctors' empathy on patients' NK subset could be completely explained through the patients' stigma, self-efficacy, and anxiety. The mechanism of the influence of the doctors' empathy on the patients' NK subset could be as follows: the doctor's empathy may first affect the patient's psychology in terms of factors such as stigma, self-efficacy, and anxiety. Then, the patient's psychology affects his or her immunity. The specific processes and explanations are discussed as follows.

First, doctors' empathy directly affected patients' selfefficacy, stigma, and anxiety. Doctors' empathy showed negative relationships with patients' stigma and anxiety and a positive relationship with patients' self-efficacy. The conclusion that doctors' empathy affects patients'

Table 7 Direct effects of doctors' empathy on patients' NK activity

\begin{tabular}{lllll}
\hline $\begin{array}{l}\text { Mediating } \\
\text { effect path }\end{array}$ & Effect & $\begin{array}{l}\text { Standard } \\
\text { error }\end{array}$ & LLCI & ULCL \\
\hline $\begin{array}{l}\text { Empathy } \rightarrow \text { NK } \\
\text { subset }\end{array}$ & -0.006 & 0.044 & -0.093 & 0.082 \\
\hline
\end{tabular}

Abbreviations: $\mathrm{LLCl}$, lower level confidence level; ULCL, upper level confidence level. 
psychological factors corresponds to the findings of previous studies. For example, Flickinger et $\mathrm{a}^{22}$ found that the empathy of doctors affected the self-efficacy of AIDS patients. Choi et $\mathrm{al}^{23}$ confirmed that the more that doctors who performed bronchoscopy were able to empathize with their patients, the less anxiety the patients felt. The finding that doctors' empathy affects patients' psychology may be explained by the following reasons: 1) doctors with strong empathy can better understand the patients' stigma and provide more compassionate care than less empathic doctors, which helps to relieve the patients' negative emotions, such as stigma. ${ }^{24}$ Similarly, doctors with high empathy are often good at taking others' perspectives and they can stand in the patients' shoes to understand patients' feelings and respond to them positively and appropriately. ${ }^{25}$ Therefore, patients are more likely to feel respect, support, attention, and love from these doctors. They are also more willing to accept the doctors' attempts to provide comfort and are more likely to cope with cancer with a more active attitude. Moreover, these patients may more routinely participate in medical care and do a better job of managing their stress. The patients of these doctors will be good at managing their emotions, meaning that they are more likely to express a range of emotions, including anger, and to seek opportunities to share their fears and concerns. These are all high self-efficacy behaviors; ${ }^{26}$ 2) doctors with high empathy can identify patients' concerns more quickly when listening to patient narratives, which helps them provide targeted health education and suggest referrals for psychiatric care. In this way, the mental health of the patients is improved, their stigma and anxiety are decreased, and their self-efficacy is increased; 3) when communicating with doctors with strong empathy, patients are willing to share their thoughts and concerns, such as those related to stigma and anxiety. Confiding is considered a process of releasing emotions that can help patients reduce the pressure they feel and establish a more positive attitude; 4) empathy promotes patient-centered care and is the basis for shared decision making. ${ }^{27,28}$ Such conditions are the embodiment of respect for patients' autonomy. These factors increase patients' dignity, which helps reduce their stigma and anxiety and enhance their self-efficacy.

Second, patients' stigma, anxiety, and self-efficacy directly affected their NK subset. Patients' stigma and anxiety showed negative relationships with NK subset, while there was a positive correlation between self-efficacy and NK subset. The effects of psychology on immunity have been widely confirmed by many studies. ${ }^{29}$ Psychoneuroimmunology is an established field, and the role of the hypothalamic-pituitaryadrenal axis has been well documented. ${ }^{30,31}$ Therefore, in this study, higher levels of stigma and anxiety (negative emotions) were associated with lower NK subsets. Conversely, higher self-efficacy (a positive emotion) was associated with greater NK subsets.

Moreover, the results showed that patients' anxiety affected their stigma and self-efficacy because once patients become anxious, they lack the motivation to cope with the disease and feel greater stigma. This finding indicates that medical staff should pay closer attention to relieving patients' anxiety.

Although no previous studies have shown a relationship between empathy and prostate cancer immunity, the impact of doctors' empathy on patients' physiological indicators, similar to this study, has been confirmed by former studies in patients with different diseases. For example, Hojat et a ${ }^{32}$ found that physicians' empathy was related to diabetic patients' hemoglobin A1c and LDL-C levels. Del Canale et $\mathrm{l}^{33}$ reported that physician empathy was associated with disease complications in diabetic patients. Cánovas et $\mathrm{a}^{34}$ confirmed that doctors' empathy helped to relieve pain in patients with moderate-to-severe chronic pain. These findings suggest that medical staff should focus on improving their empathy toward patients. Medical educators and hospital administrators should attach greater importance to empathy training for medical staff. In addition, given that patient stigma and self-efficacy were found to mediate the relationship between doctors' empathy and patients' NK subset, the authors recommend that when medical staff communicate with or provide health education to patients, they should focus on reducing patients' stigma and improving patients' self-efficacy through a variety of methods. In this way, the patients' physical and mental health can be improved.

There are various limitations to this study. First, the present research used a cross-sectional design. In practical applications, patients' stigma and self-efficacy may be related to depression, social support, and other emotions. These psychological parameters may be interrelated, and the relationships among them could not be determined in the current study. Further cohort studies that examine more psychological indicators need to be conducted. Second, many factors affect immunological functions, including sports and personal physique, and the factors included in this study were limited. Third, patients' perceptions on doctor-patient empathy should be evaluated in the future.

\section{Conclusion}

Although there are some limitations in this study, the empirical research conducted in this study confirmed that urologists' empathy affects prostate cancer patients' immune functions through influencing patients' stigma, self-efficacy, and anxiety. In addition, anxiety directly affected stigma and 
self-efficacy. Therefore, interventions that focus on patients' anxiety, stigma, and self-efficacy should be developed. As an empirical study, this research indicated that doctors' empathy affected patients' psychological parameters and immunity. Therefore, medical staff members should improve their empathy and personal relationships with patients to better maintain patients' physical health and mental health. Empathy education for medical students and medical staff in developing countries should be more actively provided.

\section{Acknowledgment}

The authors thank all the patients who generously attended the study sessions at such a difficult time in their lives and all the doctors who participated in the study.

\section{Disclosure}

The authors report no conflicts of interest in this work.

\section{References}

1. Watts S, Prescott P, Mason J, McLeod N, Lewith G. Depression and anxiety in ovarian cancer: a systematic review and meta-analysis of prevalence rates. BMJ Open. 2015;5(11):e007618.

2. Mottet N, Bellmunt J, Bolla M, et al. EAU guidelines on prostate cancer. Part II: treatment of advanced, relapsing, and castration-resistant prostate cancer. Actas Urol Esp. 2011;35(10):565-579.

3. Garssen B, Boomsma MF, Beelen RH. Psychological factors in immunomodulation induced by cancer surgery: a review. Biol Psychol. 2010;85(1):1-13.

4. Andersen BL, Thornton LM, Shapiro CL, et al. Biobehavioral, immune, and health benefits following recurrence for psychological intervention participants. Clin Cancer Res. 2010;16(12):3270-3278.

5. Lelorain S, Brédart A, Dolbeault S, Sultan S. A systematic review of the associations between empathy measures and patient outcomes in cancer care. Psychooncology. 2012;21(12):1225-1264.

6. Preston SD, de Waal FB. Empathy: its ultimate and proximate bases. Behav Brain Sci. 2002;25(1):1-20; discussion 20-71.

7. Lipp MJ, Riolo C, Riolo M, Farkas J, Liu T, Cisneros GJ. Showing you care: an empathetic approach to doctor-patient communication. Semin Othod. 2016;22(2):88-94.

8. Hojat M. Empathy and Patient Outcomes. Heidelberg: Springer International Publishing; 2016:1-10.

9. Steinhausen S, Ommen O, Antoine S, Koehler T, Pfaff H, Neugebauer E. Short- and long-term subjective medical treatment outcome of trauma surgery patients: the importance of physician empathy. Patient Prefer Adherence. 2014;8:1239-1253.

10. Hojat M, Gonnella JS, Mangione S, et al. Empathy in medical students as related to academic performance, clinical competence and gender. Med Educ. 2002;36(6):522-527.

11. Fife BL, Wright ER. The dimensionality of stigma: a comparison of its impact on the self of persons with HIV/AIDS and cancer. $J$ Health Soc Behav. 2000;41(1):50-67.

12. Pan AW, Chung L, Fife BL, Hsiung PC. Evaluation of the psychometrics of the Social Impact Scale: a measure of stigmatization. Int $J$ Rehabil Res. 2007;30(3):235-238.

13. Heitzmann CA, Merluzzi TV, Jeanpierre P, Roscoe JA, Kirsh KL, Passik SD. Assessing self-efficacy for coping with cancer: development and psychometric analysis of the brief version of the cancer behavior inventory (CBI-B). Psychooncology. 2001;10(3):206-217.

14. Merluzzi TV, Nairn RC, Hegde K, Martinez Sanchez MA, Dunn L. Self-efficacy and coping with cancer: revision of the Cancer Behavior Inventory (version 2.0). Psychooncology. 2001;10(3):206-217.
15. Zigmond AS, Snaith RD. The Hospital Anxiety and Depression Scale. Acta Psychiatr Scand. 1983;67(6):361-370.

16. Bjelland I, Dahl AA, Haug TT, Neckelmann D. The validity of the Hospital Anxiety and Depression Scale. An updated literature review. J Psychosom Res. 2002;52(2):69-77.

17. Hojat M, Mangione S, Nasca TJ, et al. The Jefferson Scale of Physician Empathy: development and preliminary psychometric data. Educ Psychol Meas. 2001;61(2):349-365.

18. Hojat M. Empathy in Patient Care: Antecedents, Development, Measurement, and Outcomes. New York: Springer; 2007:12-20.

19. Costa P, de Carvalho-Filho MA, Schweller M, et al. Measuring medical students' empathy: exploring the underlying constructs of and associations between two widely used self-report instruments in five countries. Acad Med. 2017;92(6):860-867.

20. Wen D, Ma X, Li H, Xian B. Empathy in Chinese physicians: preliminary psychometrics of the Jefferson Scale of Physician Empathy (JSPE). Med Teach. 2013;35(7):609-610.

21. Phillips B, Marshall ME, Brown S, Thompson JS. Effect of smoking on human natural killer cell activity. Cancer. 1985;56(12):2789-2792.

22. Flickinger TE, Saha S, Roter D, et al. Clinician empathy is associated with differences in patient-clinician communication behaviors and higher medication self-efficacy in HIV care. Patient Educ Couns. 2015; 99(2):220-226.

23. Choi SM, Lee J, Park YS, Lee CH, Lee SM, Yim JJ. Effect of verbal empathy and touch on anxiety relief in patients undergoing flexible bronchoscopy: can empathy reduce patients' anxiety? Respiration. 2016;92(6):380-388.

24. Duarte J, Pinto-Gouveia J, Cruz B. Relationships between nurses' empathy, self-compassion and dimensions of professional quality of life: a cross-sectional study. Int J Nurs Stud. 2016;60:1-11.

25. Martin L, Emilie B, Franck Z, Serge S. To be or not to be empathic: the combined role of empathic concern and perspective taking in understanding burnout in general practice. BMC Fam Pract. 2014; 15(1):1-7.

26. Merluzzi T, Philip E, Yang M, Heitzmann C, Conley C. Assessing selfefficacy for coping with cancer: exploratory (EFA) and confirmatory factor analyses (CFA) of version 3 of the cancer behavior inventory (CBI). Psychooncology. 2015;24:106-107.

27. Thompson C, Barforoshi S, Kell C, Banerjee D. Uncovering the patient experience: empathy mapping promotes patient-centered care for improved heart failure patient outcomes. J Card Fail. 2016; 22(8):S87-S88.

28. Charles C, Gafni A, Whelan T. Self-reported use of shared decisionmaking among breast cancer specialists and perceived barriers and facilitators to implementing this approach. Health Expect. 2004; 7(4):338-348

29. Segerstrom SC, Miller GE. Psychological stress and the human immune system: a meta-analytic study of 30 years of inquiry. Psychol Bull. 2004;130(4):601-630.

30. Maier SF, Watkins LR, Fleshner M. Psychoneuroimmunology The interface between behavior, brain, and immunity. Am Psychol. 1994; 49(12):1004-1017.

31. Pariante CM, Lightman SL. The HPA axis in major depression: classical theories and new developments. Trends Neurosci. 2008;31(9): 464-468.

32. Hojat M, Louis DZ, Markham FW, Wender R, Rabinowitz C, Gonnella JS. Physicians' empathy and clinical outcomes for diabetic patients. Acad Med. 2011;86(3):359-364.

33. Del Canale S, Louis DZ, Maio V, et al. The relationship between physician empathy and disease complications: an empirical study of primary care physicians and their diabetic patients in Parma, Italy. Acad Med. 2012;87(9):1243-1249.

34. Cánovas L, Carrascosa AJ, García M, et al; Empathy Study Group. Impact of empathy in the patient-doctor relationship on chronic pain relief and quality of life: a prospective study in Spanish pain clinics. Pain Med. Epub 2017 Jul 13. 


\section{Publish your work in this journal}

Patient Preference and Adherence is an international, peer-reviewed, open access journal that focuses on the growing importance of patient preference and adherence throughout the therapeutic continuum. Patient satisfaction, acceptability, quality of life, compliance, persistence and their role in developing new therapeutic modalities and compounds to optimize

clinical outcomes for existing disease states are major areas of interest for the journal. This journal has been accepted for indexing on PubMed Central. The manuscript management system is completely online and includes a very quick and fair peer-review system, which is all easy to use. Visit http://www. dovepress.com/testimonials.php to read real quotes from published authors.

Submit your manuscript here: http://www.dovepress.com/patient-preference-and-adherence-journal 